\title{
Prestressed concrete using carbon fibre reinforced plastic (CFRP) strands
}

\author{
A. Maissen, C. A. M. de Smet
}

Section Concrete Structures, Swiss Federal Laboratories for Materials Testing and Research (EMPA), CH-8600 Dübendorf, Suitzerland

\section{INTRODUCTION}

In a joint project carried out by EMPA and the company AVT, Anker und Vorspanntechnik AG, Tafers, with additional support from the Swiss

Commission for Technology and Innovation (CTI), the behaviour of prestressed concrete beams which were reinforced using CFRP strands was investigated. The tests were carried out on $17 \mathrm{~m}$ long two-span beams made of prestressed concrete with an I cross-section. The first test sample was prestressed using steel strands and was used as basis test for comparison with samples having the same basic structure but prestressed using CFRP strands.
Table 1 - Summary of the important parameters of the test samples

\begin{tabular}{|c|c|c|c|c|c|}
\hline $\begin{array}{c}\text { Test sample } \\
\text { designation }\end{array}$ & $\begin{array}{c}\text { Prestressing } \\
\text { element }\end{array}$ & $\begin{array}{c}\text { Type of } \\
\text { prestressing }\end{array}$ & $\begin{array}{c}\text { Prestressing } \\
\text { level [\%] }\end{array}$ & $\begin{array}{c}\text { Prestressing } \\
\text { force Vo [kN] }\end{array}$ & $\begin{array}{c}\text { Mild reinforcing } \\
\text { in the tension zone }\end{array}$ \\
\hline DTR 1 & $\begin{array}{c}5 \times \text { 0.5" } \\
\text { steel strands }\end{array}$ & bonded & 70 & 637 & $4 \varnothing 6 \mathrm{~mm}$ \\
\hline DTR 3 & $\begin{array}{c}6 \times \text { CFRP } \\
\text { strands }\end{array}$ & unbonded & 50 & 501 & $4 \varnothing 6 \mathrm{~mm}$ \\
\hline DTR 4 & $\begin{array}{c}6 \times \text { CFRP } \\
\text { strands }\end{array}$ & bonded & 50 & 501 & $4 \varnothing 6 \mathrm{~mm}$ \\
\hline DTR 5 & $\begin{array}{c}6+2 \text { CFRP } \\
\text { strands }\end{array}$ & bonded & 50 & $\begin{array}{c}501 \text { span } \\
668 \text { support }\end{array}$ & $4 \varnothing 6 \mathrm{~mm}$ \\
\hline
\end{tabular}

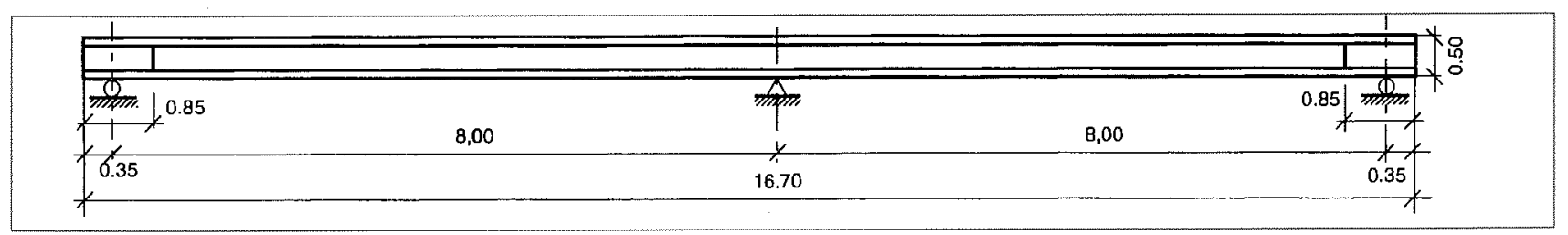
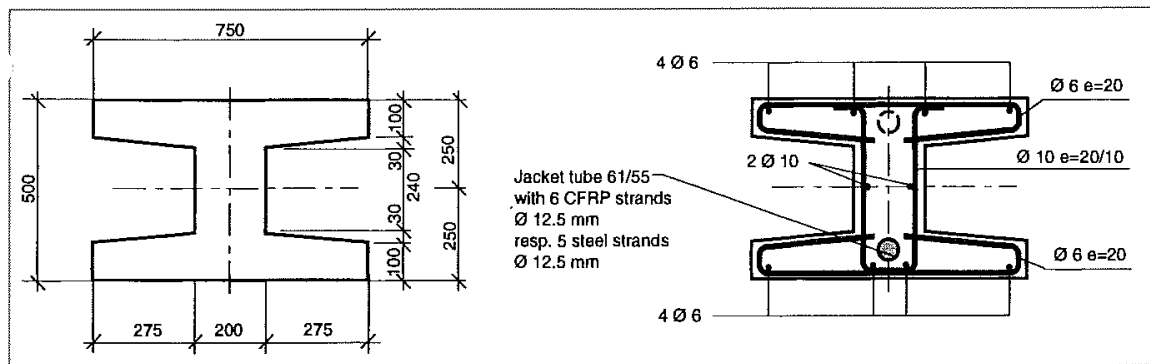

Fig. 2 - Normal cross section with formwork and reinforcement.

Fig. 3 - Cable geometry of the two-span beam.

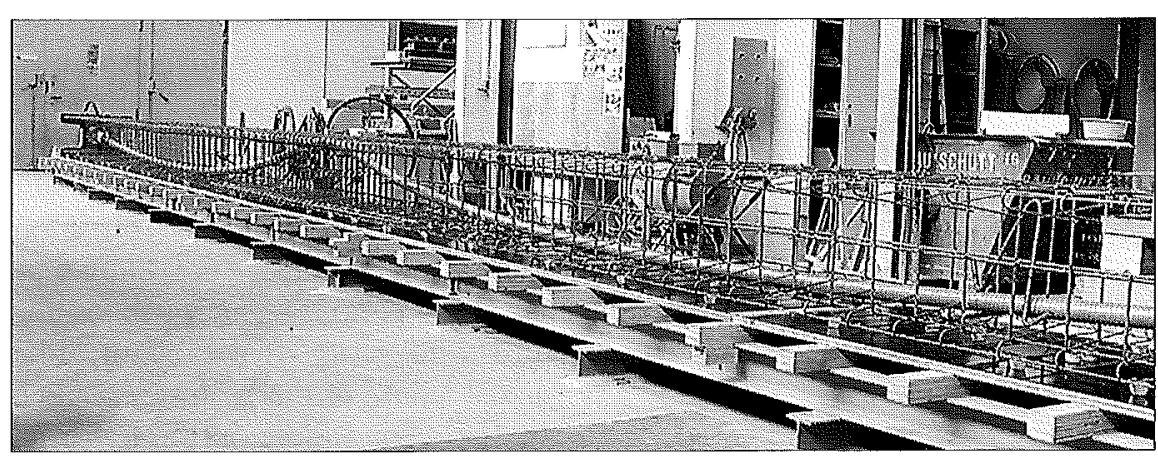

\section{TEST PROGRAM}

The test program can be seen in Table 1 which contains a list of the test samples and the most important parameters.

\section{TEST SAMPLES}

The span to depth ratio was 16:1. The test samples DTR 3 and DTR 4 were prestressed with tendons each consisting of 6 CFRP strands with $12.5 \mathrm{~mm}$ diameter; test sample DTR 5 was prestressed with 6 continuous strands and 2 additional strands over the centre support. Test sample DTR 1, in contrast, was prestressed with a tendon consisting of 5 steel strands each with diameter 0.5". Figs. 1 to 3 
contain the most important data on formwork, mild reinforcement and prestressing of the test samples selected.

\section{PRESTRESSING ELEMENTS USED}

The most important technical data of the two strand types is listed in Table 2.

Fig. 4 shows the load/strain curve for a $12.5 \mathrm{~mm}$ diameter CFRP strand and a 0.5" diameter steel strand. This figure indicates clearly the difference in behaviour of the two materials: on the one hand, the elasticity of the CFRP strands until the break occurs and, on the other hand, the elasto-plastic behaviour of the steel strands.

\begin{tabular}{|l|c|c|}
\hline \multicolumn{3}{|c|}{ Table 2 - Technical data of the strands used } \\
\hline Designation & CFRP-strands $\varnothing 12.5$ & $0.5 "$-steel strands \\
\hline Cross-section & $76 \mathrm{~mm}^{2}$ & $100 \mathrm{~mm}^{2}$ \\
\hline Yield stress & - & $1685 \mathrm{~N} / \mathrm{mm}^{2}$ \\
\hline Ultimate tensile strength & $2170 \mathrm{~N} / \mathrm{mm}^{2}$ & $1840 \mathrm{~N} / \mathrm{mm}^{2}$ \\
\hline Ultimate load & $165 \mathrm{kN}$ & $190 \mathrm{kN}$ \\
\hline Tensile modules & $140000 \mathrm{~N} / \mathrm{mm}^{2}$ & $195000 \mathrm{~N} / \mathrm{mm}^{2}$ \\
\hline Elongation at break & $1.6 \%$ & $4.8 \%$ \\
\hline
\end{tabular}

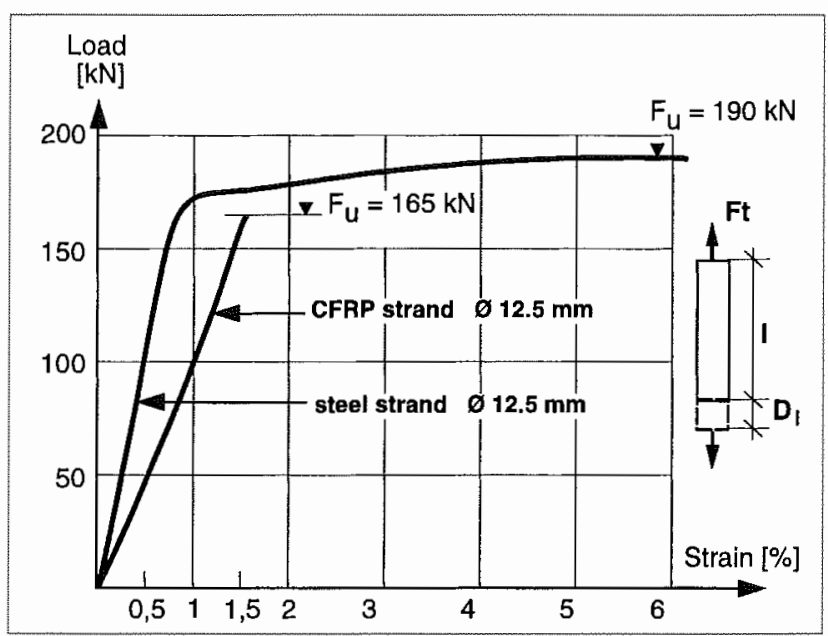

Fig. 4 - Load versus strain curves.

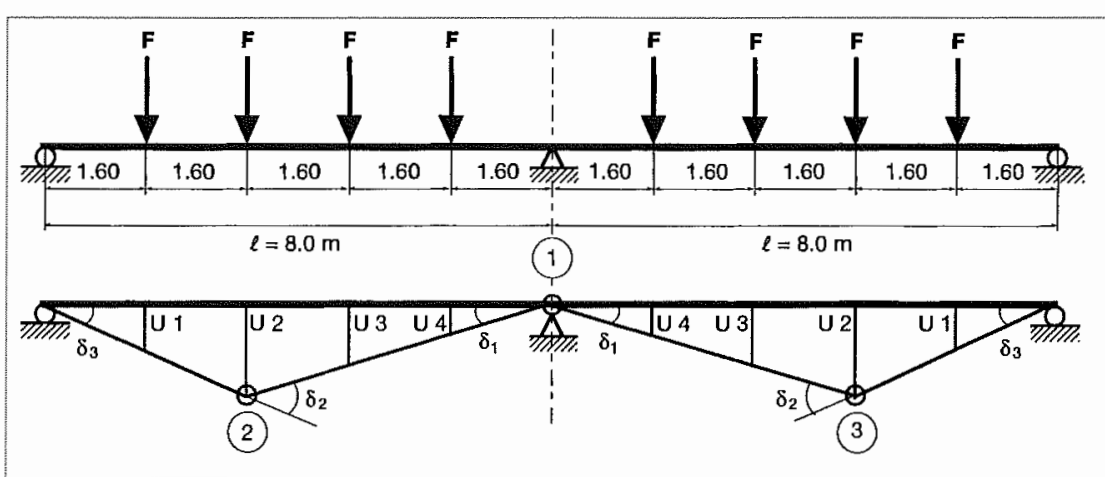

Fig. 5 - Static system and failure mechanism of the prestressed concrete beam, (1): First plastic* hinge over the centre support, (2) (3): Second and third plastic* hinge in both spans ( $*=$ only for DTR 1 ).

\section{TEST RESULTS}

\subsection{Fracture behaviour of bonded steel prestressed beam DTR 1}

DTR 1 was prestressed using steel strands and served as basis test for the comparison with similar samples prestressed using CFRP strands. Fig. 5 shows a schematic drawing of the static system and the failure mechanism of the prestressed concrete beam. This mechanism was used to determine the ultimate load theoretically for beam DTR 1 and 3, and it also corresponds to the actual conditions in the fractured conditions. Fig. 7 shows the load/deflection curves of the two span beams. In this illustration, the vertical deflections in the centre of both spans are shown as a function of the test load, whereby the curve can be followed until failure occurs.

In the static test, the sample exhibited the usual classical failure behaviour of a steel prestressed concrete beam. The plastic hinge above the centre support point started to form due to the yielding of the steel strands. However, the ultif mate load was not reached at this point because the load of the prestressing cable in the field range at this time was still below the yielding limit. Therefore, it was still possible to increase the load of the beam, at which point the deformation increased considerably. Finally, the beam failed when a second plastic hinge formed in the right hand span.

\subsection{Fracture behaviour of unbonded CFRP prestressed beam DTR 3}

For a schematic drawing of the static system and the failure mechanism of beam DTR 3, again see Fig. 5. The first hinge occurred above the centre support. In the end phase, the crushing of the concrete in the compression zone in hinge (2) caused failure of the beam construction. At the same time, partial crushing of the concrete was also produced in hinges (1) and (3). However, here the pressure force could still be transferred. The two span beam prestressed with unbonded CFRP strands also exhibited classical failure behaviour. At the locations with the highest loads - above the centre supports and in both spans - three quasi-elastic hinges were formed. This created a known fracture mechanism for a static indeterminate supported beam. Outside the hinges mentioned, no further cracks occurred, which is due to the type of prestressing which in this case was unbonded. The formation of hinges in this static system is due to the relatively large spare elasticity of the CFRP strands (prestressing level: $50 \%)$. This is why failure did not occur immediately after the formation of the first hinge above the centre support, thus permitting increased loading and deforming of the beam. The actual failure of the beam was caused by the second hinge in the left hand 

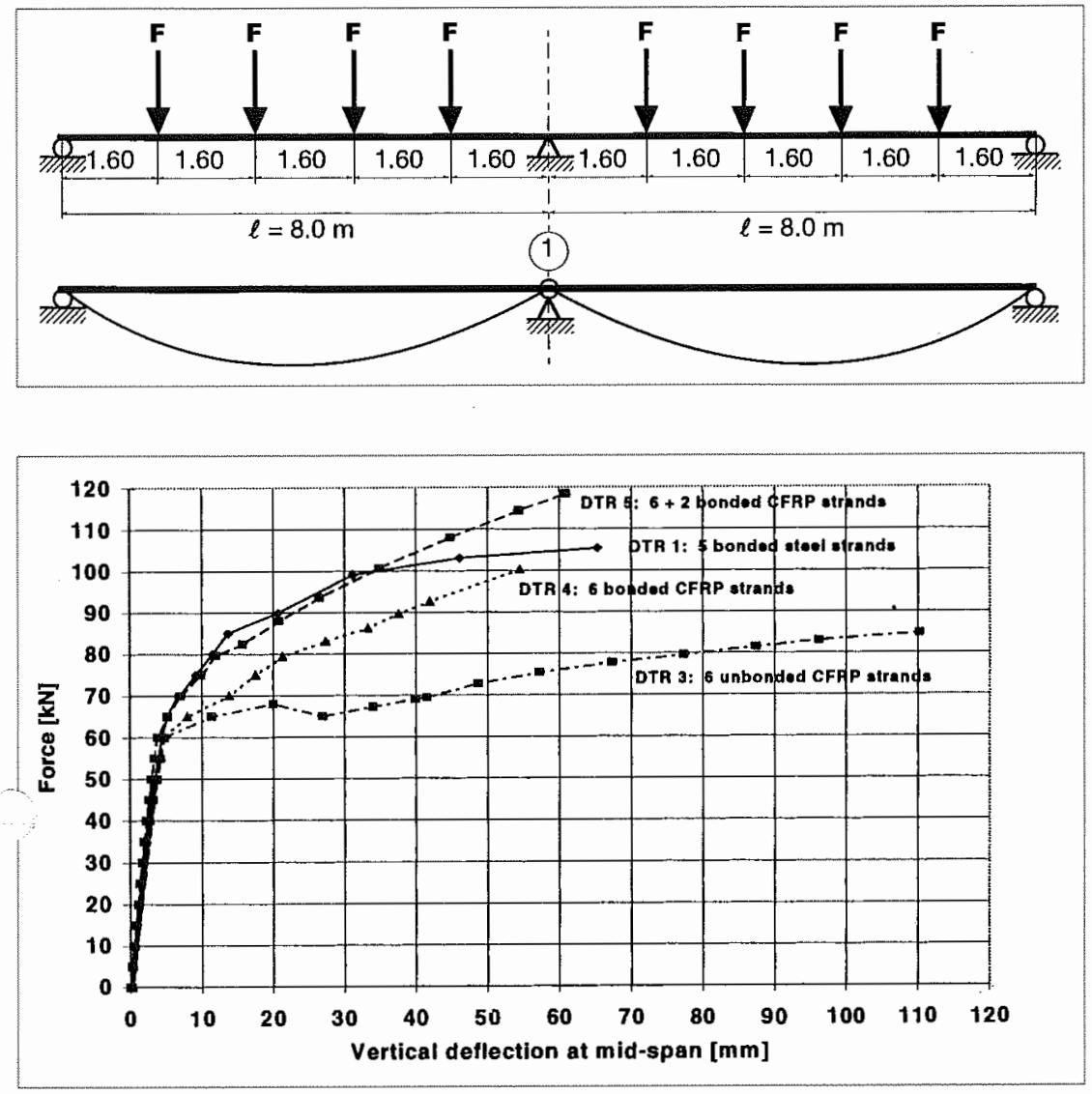

Fig. 6 - Static system and failure mechanism of the concrete beam (1): Fracture point above the centre support in the first test phase.
Fig. 7 - Load/deflection curves of prestressed concrete beams DTR 1, 3, 4 and 5 .

\section{EVALUATION}

The most important results of the tests can be summarised as follows:

- Concrete prestressed using CFRP tendons is basically feasible for statically indeterminate systems.

- In practical use, concrete pre-

span where the concrete pressure zone was partially crushed. However, the six CFRP strands remained intact. Almost simultaneously, a hinge occurred in the right hand span, which, however, was not so marked because its concrete pressure zone was only partially crushed. For the load/deflection curves see Fig. 7. The two span beam prestressed using 6 CFRP strands exhibited good deformation characteristics. The largest vertical deflection in the span was in fact $110.2 \mathrm{~mm}$ which corresponds to a $1 / 73$ deflection to span ratio. The failure characteristics can therefore be described as ductile.

\subsection{Fracture behaviour of bonded CFRP prestressed beam DTR 4}

Fig. 6 shows a schematic drawing of the static system and the failure mechanism.

The two-span CFRP prestressed beam DTR 4 exhibited a failure behaviour that differed significantly from that of steel prestressed beam DTR 1. At the location with the greatest load, which was at the centre point, all six CFRP strands broke when the fracture moment was reached. A transposition of the load (moment compensation) as with beam DTR 1, and thus an increase of the ultimate load, was therefore not possible here due to the pure elastic deformation characteristics of the CFRP strands. This disadvantage can be compensated by arranging additional strands above the centre support, so that the fracture moment above the centre support and in the spans is equalised to a great extent. This was proven on beam DTR 5. stressed by CFRP does not differ from concrete prestressed in the conventional way using steel. This can be seen from the linearity of the curves in the elastic range in which all curves are practically identical.

- The CFRP prestressed beams exhibit ductile failure characteristics. They differ only slightly from the steel reinforced beams (DTR 1).

- A transposition of the load (moment compensation), as with steel prestressing, is not possible with CFRP prestressed concrete because the material does not exhibit elasto-plastic deformation characteristics. However, this disadvantage can be compensated by arranging additional strands above the centre support so that the fracture moment above the centre support and in the spans is equalised to a great extent. This can be seen from the curve of beam DTR 5 (6+2 CFRP strands).

- For serviceability checks, the same design methods can be used for CFRP as for steel prestressed concrete. However, for ultimate limit checks, the pure elastic deformation behaviour of the CFRP prestressing tendons must be taken into account.

\section{REFERENCES}

[1] Maissen, A., EMPA-Report Nr. 233, 'Prestressed Concrete using Carbon Fibre Reinforced Plastic (CFRP) Strands, Statically Determinate Systems', Dübendorf, 1995.

[2] Maissen, A., EMPA-Report Nr. 237, 'Prestressed Concrete using Carbon Fibre Reinforced Plastic (CFRP) Strands, Statically Indeterminate Systems', Dübendorf, 1997. 


\title{
Characterization of unidirectional carbon fibre reinforced plastic laminates
}

\author{
Masoud Motavalli and Peter Flüeler \\ Swiss Federal Laboratories for Materials Testing and Research (EMPA), CH-8600 Dübendorf, Suitzerland
}

\section{ABSTRACT}

The purpose of the present paper is to outline a set of recommended tests in order to characterize the behavior of carbon fibre reinforced plastic laminates. The tests outlined in this contribution are classification of visual defects, dimension and density, fibre and resin content, tensile strength, apparent interlaminar shear strength, in-plane shear modulus, dynamic torsion property, static bending property, dynamic bending property, and thermal expansion coefficient.

As a selected example, results of two tensile tests on CFRP laminates are reported.

\section{BACKGROUND AND INTRODUCTION}

Structural post-strengthening is required when structures experience new conditions including load increases, load redistributions, and damages occurred due to normal usage or environmental factors. Investigations on the bonded steel plate strengthening at the Swiss Federal Laboratories for Materials Testing and Research (EMPA) have shown that long-term problems concerning corrosion behavior must be expected in the outdoor applications. For this reason and due to other considerations, steel plates were replaced by CFRP laminates. Consequently, CFRP laminates were employed for post-strengthening purposes in a variety of applications. The CFRP laminates are manufactured using a pultrusion process. Pultrusion has been practiced for over 40 years [1]. The pultrusion principle is accompanied with a continuous press. Normally, 12000 parallel filaments are pulled through an impregnated bath; thereafter they are formed into laminates under heat and cured. These laminates are unidirectional, i.e. the fibres in the laminate run only in one direction. Correspondingly, the laminate strength in the fibre direction is proportional to the fibre strength, and therefore is very high compared to the transverse direction.

During the years 1984 to 1989 , CFRP laminates were successfully employed for the first time at EMPA for post strengthening of concrete beams [2]. A 80 meter long prestressed bridge with a partial reinforcement of CFRP laminates was realized in Ludwigshafen in 1991 for the first time [3]. In 1994, a method was developed at EMPA to strengthen masonry shear walls in seismically active regions with CFRP laminates [4]. In 1997, the behavior of an aluminum box beam reinforced with CFRP laminates was investigated. The structure was subjected to a temperature change of $100^{\circ} \mathrm{C}$ [5]. Prior to design and application of a post-strengthening with CFRP laminate, the behavior of the strengthening laminate should first be characterized. The purpose of the present paper is to establish a list of recommended tests in order to characterize the behavior of CFRP laminates. Such a list may help the structural engineer to choose the necessary tests for designing the laminates for post-strengthening and for the purpose of qualit, control of the product.

\section{TEST METHODS}

The most common standardized tests for the CFRP laminates may be divided into the two following categories (Cat.):

Cat. 1: Tests which are recommended for the first series of a newly developed laminate.

Cat. 2: Tests which are recommended for quality control.

\section{Cat. 1 and Cat. 2: Classifying of visual defects (ASTM D2563)}

This is a visual inspection in order to specify and classify the possible defects. Visual inspection should result in description of surface cracks and description of imperfections such as interply delamination, delamination by improper machining, alignment of fibres, dry spot, foreign inclusion, fractures, lack of fillout, porosity, etc.

\section{Cat. 1 and Cat. 2: Dimensions and density (DIN 29971)}

This test method covers the determination of dimensions as well as mass per unit area of the CFRP laminates.

\section{Cat. 1 and Cat. 2: Fibre and resin content (ASTM D3171-76 and DIN EN 2564)}

This test method covers the determination of the fibre content of CFRP laminates. The technique used is based on the dissolution of the matrix resin by a liquid medium, which does not attack the fibres.

\section{Cat. 1 and Cat. 2: Tensile Tests (ASTM D3039 and DIN EN 2561)}

This test method determines the in-plane tensile properties of CFRP laminates parallel and perpendicular to the fibre direction (see Fig. 1). Tensile tests require 